\title{
Teatro na Escola: Espaciotempo do Pensamento e da Sensibilidade
}

Profa. Ms. Marli S. C. Sitta*

Profa. Dra. Graciela Ormezzano**

Profa. Ms. Cilene M. Potrich***

\section{Considerações iniciais}

Neste artigo pretendemos divulgar uma pesquisa cuja temática tratou das significações emergentes de uma experiência estética realizada com professoras de educação básica, visando contemplar a educação do sensível por meio de atividades teatrais com foco no desenvolvimento perceptivo.

Os objetivos do estudo foram compreender o significado da experiência estética teatral no processo de ensino e de aprendizagem; promover e valorizar um saber mais sensível na escola e perceber a contribuição dos jogos e exercícios teatrais do Teatro do Oprimido de Augusto Boal (1998) para as professoras participantes. O sentido de experiência estética teatral está associado, neste trabalho, à capacidade sensível do ser humano de organizar os estímulos que lhe alcançam o corpo, para que ele sinta e perceba a interdependência dos múltiplos aspectos inerentes à condição humana, potencializando a vida.

Os referenciais teóricos permitiram agrupar idéias de vários autores, juntamente com a proposta do Teatro do Oprimido de Augusto Boal (1998), que, de algum modo, têm uma visão de inteireza em contrapartida à excessiva fragmentação do conhecimento observada na escola.

Nesta investigação utilizamos uma metodologia de cunho fenomenoló-

* Marli S. C. Sitta, mestre em Educação (UPF), Coordenadora do Grupo Viramundos, professora da rede estadual de ensino do Rio Grande do Sul.

** Graciela Ormezzano, doutora em educação (PUCRGS), professora e pesquisadora do curso de Educação Artística e do Programa de Pós-Graduação em Educação - UPF.

*** Cilene M. Potrich, mestre em Educação (PUCRGS), professora do curso de Educação Artística:Artes Plásticas, Pedagogia e Publicidade e Propaganda - UPF. 
gico, desenvolvida conforme os passos propostos por Giorgi e Comiotto, citados por Ormezzano e Torres (2002). A compreensão fenomenológica das entrevistas, por sua vez, permitiu descrever e interpretar as essências e as respectivas dimensões emergidas do fenômeno em estudo. O campo de ação foi a Escola Estadual de Ensino Médio Amantino Vieira Hoffmann, na cidade de André da Rocha, Rio Grande do Sul. As entrevistadas foram dez professoras de diversas áreas do conhecimento, todas da escola pública mencionada, atuando da educação infantil ao ensino médio, que participaram de sete encontros, totalizando quarenta horas/aula.

As atividades foram desenvolvidas seguindo os passos: aquecimento, desenvolvimento e encerramento (ORMEZZANO, TORRES, 2003). A cada encontro eram definidos pelas participantes o tema e os objetivos do encontro seguinte, de acordo com os quais eram planejados os exercícios e os jogos teatrais do Teatro do Oprimido de Augusto Boal (1998) a serem trabaIhados, conforme as cinco categorias: I- Sentir tudo que se toca; II- Escutar tudo que se ouve; III- Ativar os vários sentidos; IV- Ver tudo que se olha; VA memória dos sentidos. Esses jogos e exercícios foram explorados coletivamente e estiveram vinculados ao desenvolvimento dos sentidos corporais. Neles, o autor mencionado mostra o teatro como uma linguagem, dentre outras linguagens possíveis, capaz de criar caminhos por meio dos quais as pessoas possam amenizar algumas respostas de impulsos mecânicos que privam o corpo de atuações mais originais, criativas e espontâneas. Nesse sentido, comenta: "Nós respiramos com o corpo todo: com os braços, com as pernas, os pés, mesmo que os pulmões e o aparelho respiratório tenham uma importância prioritária no processo. Nós cantamos com o corpo todo [...]. Fazemos amor com o corpo inteiro [...]" (BOAL, 1998: 88).

Ao final dos sete encontros, as dez professoras responderam à questão: "O que significou para você esta experiência de educação estética teatral?" A entrevista foi gravada, transcrita e compreendida por meio do método fenomenológico, citado por Ormezzano e Torres (2003). Foi necessário colocar em suspensão alguns preconceitos ou julgamentos prévios e permanecer fiel ao sentido das informações trazidas pelas participantes, permitindo o fenômeno emergir espontaneamente e do qual surgiram três essências, compostas pelos achados das dimensões fenomenológicas.

Visando descrever e interpretar as essências emergentes, não explicálas, apresentamos cada uma delas buscando pontos de aproximação com a educação do sensível. A primeira essência fala sobre o sentido da educação considerando os cinco sentidos; a segunda, refere-se à estética como um modo de pensar, sentir e experimentar; a terceira focaliza o processo de humanizar e socializar a escola. 


\section{O sentido da educação em todos os sentidos}

Nesta essência as entrevistadas manifestaram terem se sentido apoiadas, estimuladas e valorizadas através das experiências teatrais. Consideraram que foi possível realizar uma ressignificação do seu fazer pedagógico porque refletiram sobre sua prática em sala de aula. A reflexão e os exercícios permitiram-Ihes descobrir suas limitações, mas também suas habilidades, o que lhes trouxe maior autoconfiança para o exercício da profissão de educadoras, ou seja, proporcionando-lhes conhecimentos mais significativos, mais aproximados do seu cotidiano e do da escola, capazes de aproximá-las da história e dos bens culturais da sociedade.

Na dimensão de valorização profissional e auto-estima as participantes puderam realizar uma espécie de "revisão profissional" que evidenciou possibilidades e perspectivas de futuras reformulações em seu fazer pedagógico. Perceberam que a prática e os conhecimentos organizados podem determinar uma ação consciente e de qualidade, podendo, assim, resultar em grande contribuição para uma cultura mais autêntica e uma educação mais prazerosa. Alguns desses aspectos foram observados nas falas das participantes, como ouvimos de M.C.:

Sempre se exigiu de nós, temos todo um processo de história em cima, principalmente política, que devemos ter o mesmo passo. Só se consegue o mesmo objetivo se todos caminharmos na mesma direção. E não é assim, acho que tinha que se valorizar mais, criar esse espaço interno, do eu, pra minha educação, eu me dar esse espaço e que os outros me permitam ter esse espaço, eu tenho que lutar pra que os outros me permitam esse espaço. Afinal eu me preparei para isso e este espaço é meu! Então, valeu a pena ter participado dos encontros, percebi que gosto das coisas que faço, e gosto de mim (risos).

No depoimento de M.C., é possível perceber que ela possui boa auto-estima, porém admite que, para ser valorizada, necessita ter uma postura bem determinada, lutar, resistir, mostrar seu valor e também ter conhecimento sobre a história da educação para saber de onde vêm alguns (pré)conceitos hoje inseridos na sua profissão e também no próprio caráter. Barbosa (2001) aponta que a falta de conhecimento sobre o passado está levando os educadores e as educadoras do Brasil a valorizarem excessivamente a novidade, numa atitude que vem contribuindo para uma espécie de fazer sem propósito determinado, ou seja, um fazer sem que haja um cuidado com sua inter-realização ou com a elaboração cuidadosa de objetivos nas atividades 
realizadas em sala de aula.

As transformações do educador aparecem a partir do discurso das entrevistadas, como fala S.J.:

[...] brincando, jogando e me expondo saí mais enriquecida dos encontros. Pude perceber algumas de minhas falhas. Hoje vejo as coisas de outra forma, fazendo com que o meu trabalho no diaa-dia fique melhor. Algumas vezes eu colocava barreiras para me proteger como se o mundo fosse só meu, mas percebi que não é, que só se tem um mundo porque se convive com os outros e a construção dele depende de todos.

Transformar, em muitos aspectos da vida humana, significa caminhar para o "novo"; permite várias direções, tanto fáceis quanto difíceis, porém sempre desafiadoras. Ao educar, para a transformação, é necessário refletir, também, sobre os limites humanos dos educadores e sobre a necessidade de serem colocadas em estado de suspensão algumas concepções já enraizadas que ficam atravancando o trânsito das idéias, ou seja, é preciso que os educadores se dispam dos pensamentos predeterminados e, parafraseando Alves (2003), permitam-se pensar sobre as próprias idéias e as da comunidade escolar de sua inserção.

Esta essência revela os conteúdos mais significativos em busca de novos desafios e relaciona a procura constante das educadoras por dar sentido às suas ações pedagógicas. Tal procura foca a sensibilidade e a humanização, que podem construir seres humanos para um pensamento criativo. Como aponta Meira (2003), direcionar a educação para o olhar sensível, num mundo onde o cálculo da máquina define os ritmos numa velocidade que ultrapassa toda reflexão, exige dos educadores em geral entrelaçar vários aspectos do saber tidos como "não sérios" em termos de ciência, como os conhecimentos artísticos e os conhecimentos culturais.

Nesse sentido, para D.C., é fundamental saber o que se passa com aquele ser humano que está na sala de aula:

Em primeiro lugar, é preciso conhecer a realidade do aluno. Saber dessa realidade se torna a aprendizagem mais abrangente e mais próxima do grupo, porque a aprendizagem só acontece se houver uma aproximação entre as pessoas envolvidas nesse processo. [...] tem muita coisa que é imposta na educação e que é difícil mudar, então é melhor buscar significados para que o aluno goste daquele conteúdo. 
O dito por D.C. vai ao encontro do escrito por Maffesoli (1996: 60): "Ao se prender, de maneira crispada, ao instituído não se pode ou não se quer apreciar a vida em seu estado nascente". Assim, é possível entender a necessidade de ressignificação das atitudes do educador para uma prática que reordene e reavalie permanentemente suas ações em prol da autonomia.

O estético: um modo de pensar, sentir e experimentar

Esta essência se configurou quando as entrevistadas manifestaram a necessidade de uma prática pedagógica mediada, simultaneamente, pela teoria e pela prática, pela razão e pela emoção, pelo sentir e pelo pensar, ou seja, de um fazer pedagógico que não apenas faça, mas que também dê sentido à educação.

De fato, os educadores, em sua maioria, estão conscientes da importância da linguagem afetiva, pela qual as idéias provoquem emoções e sensações para que a aprendizagem aconteça de forma efetiva e significativa. De acordo com Meira (2003), a educação estética é capaz de mediar a teoria e a prática, o inteligível e o sensível, e chega a nós por meio dos sentidos, dos sentimentos e da linguagem do afeto. O pensamento estético tem uma compreensão, ao mesmo tempo, universal e subjetiva, visto que implica uma resposta que qualquer pessoa pode experimentar a partir de suas emoções.

Foi possível considerar uma pedagogia do corpo quando as participantes apontaram para a necessidade de resgatar a educação do processo massificante em que muitas vezes está imersa e colocá-la numa relação abrangente, interativa, ou seja, que não restrinja a atuação do educando ao esquema mecanicista estímulo-resposta, que não desconsidere o corpo desse ser em processo educativo, reduzindo-o à condição de uma dimensão humana "sem prestígio" na escola. Na visão de Duarte Júnior (2001:125),"[...] grande parte de nosso agir cotidiano fundamenta-se nesse saber corporal básico, primitivo em sua origem, mas com enorme potencial para ser desenvolvido e lapidado, ou seja, educado".

Segundo B.A., as experiências estéticas mostraram-lhe uma nova maneira de ministrar as aulas: "Sabe, aquela atividade que a gente propõe para o aluno: senta e faz o que o professor está propondo! Ela pode ser feita de outra maneira usando o corpo. Ele vai se 'soltar' e aprende com maior facilidade". Esta entrevistada percebeu que a expressão corporal realizada através dos exercícios teatrais pode deixar o aluno agir de forma mais livre e espontânea, ficando mais receptivo; portanto, aprendendo de forma mais significativa. 
Ao falar sobre a alegria de educar por meio do teatro as entrevistadas consideraram que vêem nas artes cênicas uma possibilidade importante de tornar a aprendizagem, além de mais alegre e prazerosa, reveladora de pensamentos e sentimentos. Suas falas apontam, de certa forma, tanto para o sentido subjetivo como para o significado social do teatro, excelente veículo de inclusão. Isso é possível perceber nas palavras de M.S.:

[...] o teatro pode auxiliar numa aprendizagem mais eficaz. Acredito que cada vez mais os professores precisam incorporar essa magia do teatro dentro da sua sala de aula, porque o teatro deixa o ambiente alegre, desperta a curiosidade nos alunos, faz eles participarem e ter vontade de realizar o trabalho. Porém, os alunos só vão participar e fazer se eles virem antes o prazer no professor. O professor deve participar das atividades teatrais junto com o aluno para incentivá-lo.

As atividades e os jogos teatrais podem ser mediadores da vida real do aluno para a vivência estética do imaginário, constituindo-se numa fonte preciosa de maturação e desenvolvimento do cérebro humano e, também, num exercício de "treinamento" de futuros papéis que poderá vir a exercer. Na perspectiva de Duarte Júnior (2001: 135), "[...] a ficção, a imaginação daquilo que ainda não é, mas poderia ser, consiste, pois, numa das mais eficazes ferramentas de que dispõe a humanidade para a criação do saber".

Nesta essência aparece também a relação espaço-tempo no processo de aprendizagem, como é possível observar nas considerações de E.X.:

[...] faltam tempo e espaço para atividades de reflexão sobre a gente mesmo e nossas ações. Geralmente, esse tempo e espaço são usados para discussões de conteúdos a serem dados aos alunos: faça assim, faça assado. Nós somos humanos, todo o dia a gente acerta e a gente erra, mas eu nunca tive, nos vinte anos que sou professora, momentos para ver esses pontos. Eu nunca fiz isso, mas agora, com esses encontros eu pude refletir.

No depoimento de E.X. fica evidenciada a importância de espaços nos quais, por meio de uma linguagem clara e simples, possam abrir-se indagações que encaminhem às suas próprias reflexões. Para Mèlich (1994), o ser humano não se limita a adaptar-se ao meio, nem simplesmente a transformá-lo. Por ser humano, quer dar sentido ao meio em que vive e, então, ao atribuir-lhe significação, rompendo a temporalidade. 


\section{O processo de humanizar e socializar a escola}

Na última essência as entrevistadas evidenciam a presença do outro e afirmam que a educação vai dividindo, para não dizer esfacelando, os sujeitos que dela participam. Falta também a conexão entre os conhecimentos curriculares já programados com a vida do educando.

A alteridade na educação aparece como uma dimensão dessa essência quando as entrevistadas reconhecem um outro que emerge e afeta ou altera o modo de ser e atuar das pessoas em contato com este outro. Segundo Maffesoli (1996), a alteridade permite que os seres humanos se reconheçam em outrem a partir de outrem (um outro enquanto qualquer outro, podendo ser um objeto, por exemplo). Então, é possível dizer que a alteridade propõe multiplicações do eu e que, ao nos colocarmos no papel de outros, podemos entender melhor a importância das nossas emoções e ações e também das alheias. D.C. considerou que, ao refletir sobre ela mesma, pôde aproximarse com maior facilidade dos seus alunos. Declarou textualmente:

Eu consegui trabalhar com aquelas dificuldades que os alunos têm por causa de sua história particular. Entendo que às vezes a gente trata o "outro" de maneiras diferentes, achando que este "outro" tem que fazer a coisa do jeito que a gente quer. Mas quando a gente se põe no lugar dele é diferente. Consegui me colocar no lugar do "outro", ou seja, do meu aluno, e bastante! Assim, o grupo se uniu mais. Com as atividades pude refletir sobre os meus alunos e sobre mim mesma.

A esse respeito, Merleau-Ponty (1999: 54) aponta que "[...] é na dor do outro que posso reconhecer a minha própria dor; é no azul do outro que posso reconhecer meus próprios azuis; é na dúvida do outro que reconheço minhas próprias dúvidas". No entanto, é exatamente aí que educandos e educadores podem reconhecer a si próprios e permitir-se ver os outros como eles são, num convite a melhores maneiras de ser e de agir, interferindo na realidade da qual fazem parte.

As entrevistadas apontam para os paradigmas educacionais emergentes quando abordam a visão de totalidade típica da arte, neste caso, do teatro. De acordo com essa visão, os problemas atuais no âmbito educacional não podem ser abordados isoladamente dos demais problemas que afetam o mundo. Assim, por exemplo, B.A. comentou: "Percebi meu aluno na totalidade enquanto realizava as atividades. Ele usava o corpo todo, se soltava mais, se percebia melhor, sentindo a presença dos outros colegas e 
do professor, integrava-se melhor ao seu ambiente. Isso fazia bem a ele e a mim também." Esta entrevistada referiu ainda que, por meio das atividades teatrais pôde ter uma sensação de inteireza, de integralidade, o que a fez ampliar sua percepção, confirmando, assim, o caráter participativo e envolvente do teatro. Concordamos com Capra (1996), quando diz que os problemas educacionais são sistêmicos, ou seja, estão dentro de um contexto e dizem respeito ao mundo todo, não apenas às partes que estão diretamente ligadas a um problema específico.

Outra dimensão presente nesta essência é a que se refere à utopia desejável e ao sonho aparecendo nas palavras de M.Z.:

É isso que me move: a busca para ser a cada dia um pouco meIhor, como pessoa e como profissional e os encontros me motivaram para ir em frente e lutar por aquilo que acredito. Senti-me amparada, apoiada e estimulada. Sou movida a estímulos. Como é bom ouvir pessoas que digam que vale a pena lutar pela educação. Eu acredito muito no poder que a educação tem para mudar e transformar as pessoas e a sociedade.

Na fala desta entrevistada é possível perceber um comprometimento marcante. Paulo Freire (2000) aponta que uma educação progressista jamais pode, em nome da ordem e da disciplina, castrar a altivez tanto do educando quanto do educador. Ao contrário, pode incentivar educandos e educadores a se moverem no sentido de aproveitar toda oportunidade para testemunhar o compromisso deles com a realização de um mundo melhor.

\section{Considerações finais}

Pelo evidenciado nesta investigação, os jogos e exercícios teatrais do Teatro do Oprimido de Augusto Boal (1998) mostraram-se eficientes no desenvolvimento de estratégias possíveis para enfrentar as incertezas que cerceiam nossa realidade educacional.

A experiência estética teatral depende de um aprendizado e, à medida que os códigos estéticos forem familiares a quem a eles estiver exposto, não como um adereço ou divertimento, mas como parte fundamental e essencial da realidade, a própria maneira de sentir irá se refinando, tornando as pessoas mais sensíveis às sutilezas da vida, aos meandros do mundo interior e exterior. Assim, será intensificada a percepção do estar no mundo, do conhecer, reconhecendo que somos sujeitos inalienáveis, únicos e capazes, possuidores de um saber corporal fundador de todos os demais saberes, por mais abstratos que sejam, permitindo o nosso processo de reflexão. 
Ao final dos encontros foi possível perceber que as participantes apontavam para significativos caminhos de reorganização do seu papel como educadoras na construção de um saber sensível e inteligível, visto que o teatro é capaz de dar sua contribuição ao considerar o ser humano em sua multidimensionalidade.

Portanto, com esta investigação, pensamos ter conseguido ampliar o papel do teatro e seus objetivos na educação básica, para tornar educadores de diversas áreas mais conscientes do seu compromisso social e mais sensíveis não somente às suas dimensões corporal e psíquica, mas também ao reconhecimento da corporeidade de seus educandos. Reconhecendo professores, alunos, funcionários e pais como integrantes do grande sistema da escola, instituição inserida numa cultura, numa sociedade e num ambiente natural. A vida da comunidade escolar, compreendida em termos de redes humanas, cria pensamentos e significados que podem originar novas formas comunicacionais.

\section{Notas}

Deficiência mental é um funcionamento intelectual geral significativamente abaixo da média, oriunda do período de desenvolvimento, concomitantemente associadas a duas ou mais áreas da conduta adaptativa ou da capacidade do individuo em responder as demandas da sociedade, nos seguintes aspectos: comunicação; cuidados pessoais; habilidades sociais; desempenho na família e sociedade; independência na locomoção; saúde e segurança; desempenho escolar; lazer e trabalho. (BRASIL, 1998)

Dados atualizados através do portal eletrônico do Ministério da Educação http://portal. mec. gov.br/seesp/index.php?option=content\&task=view\&id=110

Conferência Mundial de Educação Especial com delegados representantes de 88 países e 25 organizações internacionais se reuniram em Salamanca na Espanha de 7 a 10 de junho de 1994 e resultou em uma declaração que focaliza os governos e organizações a reconhecerem a necessidade urgente de possibilitar que crianças, jovens e adultos portadores de necessidades especiais possam freqüentar as instituições regulares de ensino transformadas em instituições modernas e inclusivas.

ZDP - Zona de Desenvolvimento Proximal é um dos conceitos mais importantes de Vygotsky. Para ele o indivíduo possui, além do desenvolvimento real, ou seja, aquilo que ele pode realizar sozinho, um estágio de desenvolvimento intermediário, chamado de proximal ou potencial, correspondente 
ao que o indivíduo pode realizar com a ajuda do facilitador ou do grupo. Para mais ver Vygostky 1998.

Ver Zipes 1997 para mais informação sobre Disney e industria cultural.

Habitus conceituado por Bourdieu (1979) como um conjunto de ações ideológicas inconscientes, determinações sociais, sistema de disposição e de percepção, "estruturas estruturadas predispostas a funcionar como estruturas estruturantes", com poder para programar a produção, circulação e o consumo dos indivíduos e classes. Um conceito com potencialidade para possibilitar a observação e identificação das forças ideológicas hegemônicas ligadas aos interesses sutis dominantes. Para uma interessante análise prática deste conceito ligada ao contexto latino americano ver Canclini 1995:62;79-80.

\section{Bibliografia}

ALVES, Rubem. Alegria de ensinar. Campinas. 7.ed. Campinas: Papirus, 2003.

BARBOSA, Ana Mae. John Dewey e o ensino da arte no Brasil. São Paulo: Cortez, 2001.

BOAL, Augusto. Jogos para atores e não-atores. Rio de Janeiro: Civilização Brasileira, 1998.

CAPRA, Fritjof. O ponto de mutação. São Paulo: Cultrix, 1996.

DUARTE JÚNIOR, João-Francisco. O sentido dos sentidos: a educação (do) sensível. Curitiba: Criar, 2001.

FREIRE, Paulo. Pedagogia da indignação: cartas pedagógicas e outros escritos. São Paulo: Unesp, 2000.

MAFFESOLI, Michel. No fundo das aparências. 2. ed. Petrópolis, RJ: Vozes, 1996.

MEIRA, Marly. Filosofia da criação: reflexões sobre o sentido do sensível. Porto Alegre: Mediação, 2003.

MĖLICH, Joan-Carles. Del extraño al cómplice: la educación en la vida cotidiana. Barcelona: Anthropos, 1994.

MERLEAU-PONTY, Maurice. Fenomenologia da percepção. 2.ed. São Paulo: Martins Fontes, 1999.

ORMEZZANO, Graciela; TORRES, Maria Cecília. Máscaras e melodias: duas visões em arte e educação. 2.ed. São Miguel do Oeste: Arco Íris/Unoesc, 2003. 